\title{
The prevalence of malnutrition and impact on patient outcomes among older adults presenting at an Irish emergency department: a secondary analysis of the OPTI-MEND trial
}

\author{
Anne Griffin ${ }^{1 *}$ D, Aoife O'Neill ${ }^{2}$, Margaret O'Connor ${ }^{3,4}$, Damien Ryan ${ }^{4,5}$, Audrey Tierney ${ }^{1}$ and Rose Galvin ${ }^{2}$
}

\begin{abstract}
Background: Malnutrition is common among older adults and is associated with adverse outcomes but remains undiagnosed on healthcare admissions. Older adults use emergency departments (EDs) more than any other age group. This study aimed to determine the prevalence and factors associated with malnutrition on admission and with adverse outcomes post-admission among older adults attending an Irish ED.
\end{abstract}

Methods: Secondary analysis of data collected from a randomised controlled trial exploring the impact of a dedicated team of health and social care professionals on the care of older adults in the ED. Nutritional status was determined using the Mini Nutritional Assessment- short form. Patient parameters and outcomes included health related quality of life, functional ability, risk of adverse health outcomes, frailty, hospital admissions, falls history and clinical outcomes at index visit, 30-day and 6-month follow up. Aggregate anonymised participant data linked from index visit to 30-days and 6-month follow-up were used for statistical analysis.

Results: Among 353 older adults (mean age 79.6 years (SD $=7.0) ; 59.2 \%(n=209)$ female) the prevalence of malnutrition was $7.6 \%(n=27)$ and 'risk of malnutrition' was $28 \%(n=99)$. At baseline, those who were malnourished had poorer quality of life scores, functional ability, were more frail, more likely to have been hospitalised or had a fall recently, had longer waiting times and were more likely to be discharged home from the ED than those who had normal nutrition status. At 30-days, those who were malnourished were more likely to have reported another hospital admission, a nursing home admission, reduced quality of life and functional decline than older adults who had normal nutrition status at the baseline ED visit. Differences between the MNA SF and 6month outcomes were similar but not statistically significant.

(Continued on next page)

\footnotetext{
* Correspondence: anne.griffin@ul.ie

${ }^{1}$ School of Allied Health, Faculty of Education and Health Sciences, Health

Implementation Science and Technology, Health Research Institute, University of Limerick, Limerick V94 T9PX, Ireland

Full list of author information is available at the end of the article
}

(C) The Author(s). 2020 Open Access This article is licensed under a Creative Commons Attribution 4.0 International License, which permits use, sharing, adaptation, distribution and reproduction in any medium or format, as long as you give appropriate credit to the original author(s) and the source, provide a link to the Creative Commons licence, and indicate if changes were made. The images or other third party material in this article are included in the article's Creative Commons licence, unless indicated otherwise in a credit line to the material. If material is not included in the article's Creative Commons licence and your intended use is not permitted by statutory regulation or exceeds the permitted use, you will need to obtain permission directly from the copyright holder. To view a copy of this licence, visit http://creativecommons.org/licenses/by/4.0/ The Creative Commons Public Domain Dedication waiver (http://creativecommons.org/publicdomain/zero/1.0/) applies to the data made available in this article, unless otherwise stated in a credit line to the data. 
(Continued from previous page)

Conclusion: Over one-third of older adults admitted to an Irish ED are either malnourished or at risk of malnourishment. Malnutrition was associated with a longer stay in the ED, functional decline, poorer quality of life, increased risk of hospital admissions and a greater likelihood of admission to a nursing home at 30 days.

Trial registration: Protocol registered in ClinicalTrials.gov, ID: NCT03739515, first posted November 13, 2018.

Keywords: Malnutrition screening, Health and social care professionals, Emergency department, Older adults, Hospital readmission

\section{Background}

In 2018, the number of people worldwide who were over the age of 65 years outnumbered children who were under the age of five years for the first time in history. It is predicted that this cohort will more than double (from 9 to $16 \%$ ) by 2050 [1]. In Ireland, census figures from 2011 to 2016 reported that the proportion of adults aged 65 years or older increased by $19.1 \%$ [2]. Further projections from the 2016 census predict that the number of adults aged over 65 years will increase significantly from a level of 629,800 to a potential 1.6 million by 2051, with the most dramatic increase occurring among those aged over 80 years [3]. The increasing ageing population along with a higher number of individuals with multimorbidity are some of the main demographic drivers of incremental increases in Emergency Department (ED) attendances [4, 5]. In Ireland, an increase was observed in the proportion of older adults who visited the ED at least once in the year previous from 15 to $18 \%$ during 2009-2016 [6]. For older adults with frailty, the proportion with at least one overnight hospital admission increased (from 23 to $31 \%$ ) while the average number of nights spent in hospital more than doubled (from 2.7 nights to 6.5 nights) [6].

Protein-energy malnutrition, often referred to simply as malnutrition, is a condition resulting from inadequate intake or an inability to absorb and/or digest adequate energy and/or protein [7]. A strong association between malnutrition and adverse health outcomes among older adults is well documented including increased morbidity and mortality [8-10]. Nutritional vulnerability contributes to more medical complications, longer hospital stays, increased likelihood of nursing home admission and poorer quality of life [11-13]. Total costs associated with malnutrition among institutionalised and community-dwelling older adults are reported as considerably higher than those among well-nourished older adults, predominately due to higher use of health care resources - GP consultations, hospitalisations, health care monitoring, and treatments [14]. Of a limited number of studies investigating malnutrition among older adults presenting at EDs, prevalence rates are reported as 15-29\% [15-18] and have been associated with an increase in short-term mortality [16, 19].
Malnutrition screening in the ED can therefore capture a nutritionally vulnerable population that could otherwise be overlooked as not all individuals who attend the ED are admitted to hospital, where screening for malnutrition usually takes place $[11,15]$. The Mini Nutrition Assessment is a valid nutritional screening tool recommended for use by the European Society for Clinical Nutrition and Metabolism (ESPEN) guideline on clinical nutrition and hydration in geriatrics [8, 20]. It takes into account physical and mental functional impairments that regularly contribute to the development of malnutrition and thus, considers an existing risk of malnutrition $[8,21]$.

Given a dearth of information this study aimed to determine the prevalence of malnutrition among older adults from screening on admission to an Irish ED and to report the observed patient outcome factors between categories of malnutrition risk at baseline, 30-days and 6-months follow up.

\section{Methods}

\section{Study design}

This is an observational study from a secondary analysis of a single-centre randomised controlled trial, OPTIMEND, which aimed to determine and measure the impact of a dedicated health and social care professional (HSCP) team on the quality, safety, timeliness and costeffectiveness of care of older adults in the ED. The protocol for the trial is published elsewhere [22]. The OPTI-MEND study received ethical approval from the Health Service Executive (HSE) Mid-Western Regional Hospital Research Ethics Committee (ref. 103/18). Written informed consent was obtained from all study participants.

\section{Participants}

Adults aged 65 years or older who presented to the ED at the University Hospital of Limerick (UHL), between December 2018 and May 2019 (inclusive), were considered eligible for the OPTI-MEND study. Inclusion criteria required 1) the capacity (Mini-Mental State Examination 217 ) and willingness to provide informed consent; 2) baseline mobility and functional status; and 3) lower urgency defined as medical stability presenting 
with any of the complaints presented in Table 1 as per the Manchester Triage System 2-5. The exclusion criteria included: 1) aged under 65 years; 2) medically unstable; 3) neither the patient nor the carer could sufficiently communicate in English to complete consent or baseline assessment; and 4) presentation and discharge outside of HSCP operational hours ( 8 am to 5 pm, Monday to Friday) [22, 23]. A total of 392 older adults were approached to participate with 38 declining to participate and one exclusion who did not meet the inclusion criteria.

\section{Tools and procedures}

Participants of the OPTI-MEND study [22] underwent a baseline assessment of function and quality of life by one of the dedicated HSCP team (senior physiotherapist, senior occupational therapist and senior medical social worker) or a research nurse. Outcome assessment at follow-up (30-days and 6 months following index visit) was conducted via telephone.

Each participants baseline information included demographic and social details (age, sex, marital and residential status, mode of transport to ED, source of referral), the duration of patient ED stay (mean number of hours from time of arrival to discharge or admission); hospital admissions from the ED (defined as the proportion of patients who are admitted to hospital after their index visits), the duration of hospital admission after the ED index visit, assessment of frailty using the Clinical Frailty Scale [24] and, risk of adverse health outcomes using the Identification of Seniors at Risk (ISAR) [25]. The Mini Nutrition Assessment-Short Form (MNA-SF) was included as an additional measure of assessment to the original OPTI-MEND trial. The MNA-SF allows for the measurement of either body mass index (BMI) or calf circumference enabling use with individuals who are immobile or in situations where weight and height cannot be measured [20]. Previous research has established the criterion validity of this tool in healthcare settings (community, rehabilitation, residential care, and hospital) among older people. The MNA-SF is comprised of six

Table 1 Presenting complaint as per Manchester Triage System [23]

\begin{tabular}{ll}
\hline Before Medical Work-up $^{\mathbf{a}}$ & After Medical Work-up $^{\mathbf{b}}$ \\
\hline Limb problems & Chest pain \\
Falls & Shortness of breath \\
Unwell adult & Abdominal pain \\
Back pain & Headache \\
Urinary problems & \\
Ear and facial problems & \\
\hline
\end{tabular}

${ }^{\mathrm{a}}$ The health and social care professional (HSCP) team proactively treated these individuals without prior assessment by a physician ${ }^{\text {b }}$ The HSCP team awaited medical clearance prior to assessment and intervention individual components which include documenting food intake, weight loss, mobility, stress or disease, neuropsychological problems and either Body Mass Index (BMI) or calf circumference (CC). It is scored out of a possible total of 14 points with the following categories: 0-7 points: 'Malnourished', 8-11 points: 'at risk of malnourishment' and 12-14 points: 'normal nutritional status'.

\section{Outcome measures}

Adverse outcomes recorded from the index visit included ED outcome (admission, discharge home, transfer to other hospital), the hospital length of stay (measured in days), and patient's length of stay in the ED (measured in hours).

Outcome measures included the number of ED reattendance, nursing home admissions, unplanned hospital visits (and length of stay) and mortality within 30 days and 6 months of the initial index visit. Healthcare utilisation (visits to a general practitioner (GP), public health nurse, home help, private consultation, outpatient department visit, or allied health services) was captured at 30 days and 6 months after the index visit. Assessment of patient-oriented outcomes included the Barthel Index for Activities of Daily Living [26] as a global measure of functional status and the EuroQoL's 5- level of the EQ5D (EQ-5D-5 L) to measure health-related quality of life [27] assessed at baseline and follow-up (30 days and 6 months). At 30-days, functional status was measured by the change in the Barthel index from baseline to 30-days (no change, reduced function, improved function), and change in quality of life (QOL) was measured by the change in EQ-5D (no change, reduced QOL, improved QOL). At 6-months further decline in function and QOL was measured by the change from 30-days to 6-months.

\section{Statistical analysis}

Aggregate anonymised participant data linked from baseline to 30-days and 6-month follow-up were used for statistical analysis. Descriptive statistics of the study participants were conducted. Categorical data were described by counts and percentages. Continuous data that approximated a normal distribution were described using means and standard deviations. Skewed data were described using medians and interquartile ranges. Differences between patient's demographic, psychological/social, environmental/economic and physiological/ biomedical information and the MNA-SF categories were tested using Pearson's Chi-square test (or Fisher's exact test if appropriate) for categorical data. For continuous data, differences were tested using the one-way ANOVA test or Kruskal Wallis tests where appropriate. $\mathrm{Eta}^{2}$ was used to measure effect size for three or more 
groups, where $0.01,0.06$ and 0.14 represent a small, medium and large effect. Cramer's V was used to measure the size of the effect between categorical variables, with $\mathrm{V}=0.1,0.3$ and 0.5 for a small, medium and large effect, respectively. Hierarchical logistic regression models were used to further analyse associations between the MNA-SF categories and the observed decline in functional status and quality of life at follow up. A 5\% level of significance was used for all statistical tests. All statistical analysis was undertaken using SPSS Version 24.

\section{Results}

\section{Malnutrition classification}

A total of 353 patients participated with a mean age of 79.6 $(\mathrm{SD}=7.0)$ years; $59.2 \%(n=209)$ of participants were female. Using the MNA-SF screening tool, 7.6\% $(n=27)$ older adults attending the ED were categorised as malnourished, $28.0 \%(n=99)$ were categorised as at risk of malnutrition and $64.3 \%(n=227)$ had a normal nutritional status.
Table 2 presents the distribution of the component information of the MNA-SF tool as recorded in the sample of patients.

When asked about the 3 months before ED attendance, weight loss was reported by $15.5 \%(n=55)$ older adults with $5.9 \%(n=21)$ stating a loss of body weight greater than $3 \mathrm{~kg}$ in the previous 3 months. A moderate to severe decline in food intake was reported by $20.4 \%(n=72)$ older adults. Measured BMI was recorded for $13.0 \%(n=49)$ of the 353 patients, with mean BMI of $27.8(\mathrm{SD}=5.7) \mathrm{kg} / \mathrm{m}^{2}$. Among those with a BMI categorised as overweight and obese $(67.4 \%, n=31), 13 \%(\mathrm{n}=4)$ were identified as 'at risk of malnutrition' using the MNA-SF with the remainder having normal nutrition status.

\section{Participant characteristics between MNA-SF categories}

Table 3 shows the characteristics of the study participants as lower urgency patients admitted to the ED and the difference in characteristics between MNA-SF

Table 2 Prevalence (N (\%)) of states of nutrition and individual components that contribute to nutrition status according to the MNA-short form screening tool among older adults $(n=353)$ at index visit to the ED

\begin{tabular}{|c|c|c|}
\hline Malnutrition Screening & Criteria & N (\%) \\
\hline \multirow[t]{3}{*}{ MNA-SF Total } & Malnourished (MNA score 0-7 points) & $27(7.6)$ \\
\hline & At risk of malnutrition (MNA score 8-11 points) & $99(28.0)$ \\
\hline & Normal nutritional status (MNA score 12-14 points) & $227(64.3)$ \\
\hline \multicolumn{3}{|c|}{ Individual components of the MNA-SF tool } \\
\hline \multirow[t]{3}{*}{ Food intake } & Severe decrease in food intake & $13(3.7)$ \\
\hline & Moderate decrease in food intake & $59(16.7)$ \\
\hline & No decrease in food intake & $281(79.6)$ \\
\hline \multirow[t]{4}{*}{ Weight loss } & Weight loss greater than $3 \mathrm{~kg}$ & $21(5.9)$ \\
\hline & Does not know & $17(4.8)$ \\
\hline & Weight loss between 1 and $3 \mathrm{~kg}$ & $34(9.6)$ \\
\hline & No weight loss & $281(79.6)$ \\
\hline \multirow[t]{3}{*}{ Mobility } & Bed or chair bound & $7(2.0)$ \\
\hline & Able to get out of bed / chair but does not go out & $85(24.1)$ \\
\hline & Goes out & $261(73.9)$ \\
\hline \multirow[t]{2}{*}{ Stress or disease } & Yes & $74(21.0)$ \\
\hline & No & $279(79.0)$ \\
\hline \multirow[t]{3}{*}{ Neuropsychological problems } & Severe dementia or depression & $22(6.2)$ \\
\hline & Mild dementia & $37(10.5)$ \\
\hline & No psychological problems & $294(83.3)$ \\
\hline \multirow[t]{4}{*}{ BMl kg/m² $(n=49)^{a}$} & BMl less than $19 \mathrm{~kg} / \mathrm{m}^{2}$ & $6(1.7)$ \\
\hline & BMI 19 to less than $21 \mathrm{~kg} / \mathrm{m}^{2}$ & $4(1.1)$ \\
\hline & BMI $21 \mathrm{~kg} / \mathrm{m}^{2}$ to less than $23 \mathrm{~kg} / \mathrm{m}^{2}$ & $6(1.7)$ \\
\hline & BMI $23 \mathrm{~kg} / \mathrm{m}^{2}$ or greater & $33(9.3)$ \\
\hline \multirow[t]{2}{*}{ Calf circumference $(n=296)^{a}$} & CC less than $31 \mathrm{~cm}$ & $50(14.2)$ \\
\hline & CC $31 \mathrm{~cm}$ or greater & $246(69.7)$ \\
\hline
\end{tabular}

${ }^{a}$ Either the $\mathrm{BMI}\left(\mathrm{kg} / \mathrm{m}^{2}\right)$ or the calf circumference $(\mathrm{cm})$ was used to classify individuals into the MNA categories MNA mini nutritional assessment; $B M I$ body mass index; $C C$ calf circumference 
Table 3 Baseline characteristics of patients (n 353) on admission to ED according to nutrition status as categorised by the MNA-SF

\begin{tabular}{|c|c|c|c|c|c|c|}
\hline \multirow{2}{*}{ Characteristics, $\mathrm{n}(\%)$ or mean (SD) or median (IQR) } & & \multirow[b]{2}{*}{$\begin{array}{l}\text { Full } \\
\text { sample } \\
\mathrm{n}=353\end{array}$} & \multicolumn{3}{|c|}{ MNA-SF categories } & \multirow[b]{2}{*}{$\begin{array}{l}p \text {-value } \\
\text { (effect size) }\end{array}$} \\
\hline & & & $\begin{array}{l}\text { Normal } \\
\text { nutrition } \\
n=227\end{array}$ & $\begin{array}{l}\text { At risk of } \\
\text { malnutrition } \\
\mathrm{n}=99\end{array}$ & $\begin{array}{l}\text { Malnourished } \\
n=27\end{array}$ & \\
\hline \multicolumn{7}{|l|}{ Demographic information } \\
\hline \multirow[t]{2}{*}{ Sex } & Male & $\begin{array}{l}144 \\
(40.8)\end{array}$ & $\begin{array}{l}101 \\
(44.5)\end{array}$ & $36(36.4)$ & $7(25.9)$ & $0.10(0.11)$ \\
\hline & Female & $\begin{array}{l}209 \\
(59.2)\end{array}$ & $\begin{array}{l}126 \\
(55.5)\end{array}$ & $63(63.6)$ & $20(71.4)$ & \\
\hline \multirow[t]{3}{*}{ Age } & $60-74$ & $83(23.5)$ & $60(26.4)$ & $21(21.2)$ & $2(7.4)$ & $0.19(0.09)$ \\
\hline & $75-84$ & $\begin{array}{l}171 \\
(48.4)\end{array}$ & $\begin{array}{l}108 \\
(47.6)\end{array}$ & $49(49.5)$ & $14(51.9)$ & \\
\hline & $85+$ & $99(28.0)$ & $59(26.0)$ & $29(29.3)$ & $11(40.7)$ & \\
\hline \multirow[t]{4}{*}{ Marital status } & Married & $\begin{array}{l}135 \\
(38.2)\end{array}$ & $94(41.8)$ & $34(34.7)$ & $7(25.9)$ & $0.29(0.11)$ \\
\hline & Single & $51(14.4)$ & $33(14.7)$ & $14(14.3)$ & $4(14.8)$ & \\
\hline & Divorced & $11(3.1)$ & $5(2.2)$ & $6(6.1)$ & $0(0.0)$ & \\
\hline & Widowed & $\begin{array}{l}153 \\
(43.3)\end{array}$ & $93(41.3)$ & $44(44.9)$ & $16(59.3)$ & \\
\hline \multirow[t]{3}{*}{ Residential status } & Lives alone & $\begin{array}{l}153 \\
(43.3)\end{array}$ & $\begin{array}{l}103 \\
(45.4)\end{array}$ & $39(39.4)$ & $11(40.7)$ & $0.46(0.07)$ \\
\hline & Lives with family & $\begin{array}{l}183 \\
(51.8)\end{array}$ & $\begin{array}{l}115 \\
(50.7)\end{array}$ & 55 (55.6) & $13(48.1)$ & \\
\hline & Other & $17(4.8)$ & $9(4.0)$ & $5(5.1)$ & $3(11.1)$ & \\
\hline \multirow[t]{3}{*}{ Mode of Entry } & Ambulance & $\begin{array}{l}171 \\
(48.4)\end{array}$ & $98(43.2)$ & $57(57.6)$ & $16(59.3)$ & $0.17(0.10)$ \\
\hline & Private Transport & $\begin{array}{l}177 \\
(50.1)\end{array}$ & $\begin{array}{l}125 \\
(55.1)\end{array}$ & $41(41.4)$ & $11(40.7)$ & \\
\hline & Public Transport / walk in & $5(1.4)$ & $4(1.8)$ & $1(1.0)$ & $0(0.0)$ & \\
\hline \multirow[t]{3}{*}{ Source of Referral } & GP & $\begin{array}{l}124 \\
(35.1)\end{array}$ & $75(33.0)$ & $36(36.4)$ & $13(48.1)$ & $0.05(0.12)$ \\
\hline & Self-referral & $\begin{array}{l}210 \\
(59.5)\end{array}$ & $\begin{array}{l}140 \\
(61.7)\end{array}$ & $60(60.6)$ & $10(37.0)$ & \\
\hline & Other ${ }^{b}$ & $19(5.4)$ & $12(5.3)$ & $3(3.0)$ & $4(14.8)$ & \\
\hline \multirow[t]{3}{*}{ Presenting Problem } & $\begin{array}{l}\text { Acute disease / injury } \\
\text { (moderate) }\end{array}$ & $\begin{array}{l}317 \\
(89.8)\end{array}$ & $\begin{array}{l}204 \\
(89.9)\end{array}$ & $88(88.9)$ & 25 (92.6) & $0.12(0.10)$ \\
\hline & Acute disease / injury (severe) & $23(6.5)$ & $18(7.9)$ & $5(5.1)$ & $0(0.0)$ & \\
\hline & Gastro complaint & $13(3.7)$ & $5(2.2)$ & $6(6.1)$ & $2(7.4)$ & \\
\hline \multirow[t]{3}{*}{ Triage } & Orange & $36(10.2)$ & $25(11.0)$ & $9(9.1)$ & $2(7.4)$ & $0.74(0.06)$ \\
\hline & Yellow & $\begin{array}{l}295 \\
(83.6)\end{array}$ & $\begin{array}{l}187 \\
(82.4)\end{array}$ & $83(83.8)$ & 25 (92.6) & \\
\hline & Green & $22(6.2)$ & $15(6.6)$ & $7(7.1)$ & $0(0.0)$ & \\
\hline EQ-5D total ${ }^{c}$ & & $12(6)$ & $11(6)$ & $12(7)$ & $15(6.0)$ & $<0.001(0.17)$ \\
\hline EQ VAS ${ }^{c}$ & & $60(30)$ & $65(30)$ & $50(30)$ & $50(20.0)$ & $<0.001(0.19)$ \\
\hline Barthel index ${ }^{c}$ & & $18(5)$ & $18.0(5)$ & $17.0(6.0)$ & $13.0(9.0)$ & $<0.001(0.32)$ \\
\hline ISAR score ${ }^{a}$ & & $\begin{array}{l}2.52 \\
(1.2)\end{array}$ & $2.3(1.2)$ & $2.8(1.3)$ & $3.7(1.0)$ & $<0.001(0.32)$ \\
\hline Clinical frailty score ${ }^{a}$ & & $4.1(1.4)$ & $3.7(1.2)$ & $4.5(3.7)$ & $5.6(1.1)$ & $<0.001(0.41)$ \\
\hline \multirow[t]{2}{*}{ Falls past 3 months } & No & $\begin{array}{c}164 \\
(46.6)\end{array}$ & $96(42.3)$ & $57(58.2)$ & $11(40.7)$ & $0.03(0.14)$ \\
\hline & Yes & $\begin{array}{l}188 \\
(53.4)\end{array}$ & $\begin{array}{l}131 \\
(57.7)\end{array}$ & $41(41.8)$ & $16(59.3)$ & \\
\hline Hospitalised past 6 months & No & $\begin{array}{l}239 \\
(67.9)\end{array}$ & $\begin{array}{l}169 \\
(74.8)\end{array}$ & $56(56.6)$ & $14(51.9)$ & $0.001(0.20)$ \\
\hline
\end{tabular}


Table 3 Baseline characteristics of patients (n 353) on admission to ED according to nutrition status as categorised by the MNA-SF (Continued)

\begin{tabular}{|c|c|c|c|c|c|c|}
\hline \multirow{2}{*}{ Characteristics, $n(\%)$ or mean (SD) or median (IQR) } & & \multirow[b]{2}{*}{$\begin{array}{l}\text { Full } \\
\text { sample } \\
n=353\end{array}$} & \multicolumn{3}{|c|}{ MNA-SF categories } & \multirow[b]{2}{*}{$\begin{array}{l}p \text {-value } \\
\text { (effect size) }\end{array}$} \\
\hline & & & $\begin{array}{l}\text { Normal } \\
\text { nutrition } \\
n=227\end{array}$ & $\begin{array}{l}\text { At risk of } \\
\text { malnutrition } \\
n=99\end{array}$ & $\begin{array}{l}\text { Malnourished } \\
n=27\end{array}$ & \\
\hline & Yes & $\begin{array}{c}113 \\
(32.1)\end{array}$ & $57(25.2)$ & $43(43.4)$ & $13(48.1)$ & \\
\hline \multicolumn{7}{|l|}{ Outcome of index visit } \\
\hline $\mathrm{PET}^{\mathrm{c}}$ & & $\begin{array}{l}18.1 \\
(15.1)\end{array}$ & $\begin{array}{l}17.2 \\
(14.4)\end{array}$ & $18.1(17.2)$ & $22.6(11.4)$ & $<0.001(0.22)$ \\
\hline \multirow[t]{3}{*}{ Outcome } & Admission & $\begin{array}{l}220 \\
(62.3)\end{array}$ & $\begin{array}{l}162 \\
(71.4)\end{array}$ & $46(46.5)$ & $12(44.4)$ & $<0.001(0.19)$ \\
\hline & Discharge home & $95(26.9)$ & $46(20.3)$ & $40(40.4)$ & $9(33.3)$ & \\
\hline & Transfer to other hospital & $38(10.8)$ & $19(8.4)$ & $13(13.1)$ & $6(22.2)$ & \\
\hline HoLOS $^{c}$ & & $9.0(15)$ & $8(12)$ & $9(23)$ & $10(12)$ & $0.21(0.19)$ \\
\hline
\end{tabular}

Statistical difference is reported in bold between categories of nutritional status $(P \leq 0.05)$

${ }^{a}$ mean (SD) is presented

bother includes injury unit, nursing home, Out of Hours clinic, walk in clinic

cmedian (IQR) is presented

MNA mini nutritional assessment, HoLOS hospital length of stay in days, PET patient length of stay in ED in hours, EQ-5D total quality of life score, EQ VAS visual analogue scale score, ISAR score identification of seniors at risk

Table 4 Differences in reported patient outcomes across MNA-SF categories among 353 older adults at 30-day follow-up from index visit in an Irish ED

\begin{tabular}{|c|c|c|c|c|c|c|}
\hline \multirow[t]{2}{*}{ Patient outcome, n (\%) } & & \multirow{2}{*}{$\begin{array}{l}\text { Full } \\
\text { Sample }\end{array}$} & \multicolumn{3}{|l|}{ MNA categories } & $\begin{array}{l}\text { P-value } \\
\text { (Effect size) }\end{array}$ \\
\hline & & & & & & \\
\hline \multirow{3}{*}{ Functional decline } & No chan & $141(439)$ & $96(457)$ & $39(453)$ & $6(240)$ & 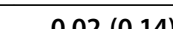 \\
\hline & Reduced function & 96 (29.9) & $52(24.8)$ & $31(36.0)$ & $13(52.0)$ & \\
\hline & Improved function & $84(26.2)$ & $62(29.5)$ & $16(18.6)$ & $6(24.0)$ & \\
\hline \multirow[t]{3}{*}{ QOL decline } & No change & $47(13.3)$ & $32(15.2)$ & $13(15.1)$ & $2(8.0)$ & $0.02(0.14)$ \\
\hline & Reduced QOL & $51(15.9)$ & $28(13.3)$ & $13(15.1)$ & $10(40.0)$ & \\
\hline & Improved QOL & $223(69.5)$ & $150(71.4)$ & $60(69.8)$ & $13(52.0)$ & \\
\hline \multirow[t]{2}{*}{ ED revisit } & No & $296(83.9)$ & $189(83.3)$ & $86(86.9)$ & $21(77.8)$ & $0.48(0.06)$ \\
\hline & Yes & $57(16.1)$ & $38(16.7)$ & $13(13.1)$ & $6(22.2)$ & \\
\hline \multirow[t]{3}{*}{ Number of ED visits } & 0 & $298(84.4)$ & $191(84.1)$ & $86(86.9)$ & $21(77.8)$ & $0.49(0.08)$ \\
\hline & 1 & $43(12.2)$ & $27(11.9)$ & $10(10.1)$ & $6(22.2)$ & \\
\hline & $2+$ & $12(3.4)$ & $9(4.0)$ & $3(3.0)$ & $0(0.0)$ & \\
\hline \multirow[t]{2}{*}{ Hospital admissions } & No & $309(87.5)$ & $203(89.4)$ & $87(87.9)$ & $19(70.4)$ & $0.02(0.15)$ \\
\hline & Yes & $44(12.5)$ & $24(10.6)$ & $12(12.1)$ & $8(29.6)$ & \\
\hline HoLOS at revisit ${ }^{a}$ & & $8.4(4.7)$ & $8.7(4.9)$ & $7.3(4.2)$ & $9.3(5.7)$ & $0.46(0.21)$ \\
\hline \multirow[t]{2}{*}{ Healthcare use } & No & $110(31.2)$ & $58(25.6)$ & $42(42.4)$ & $10(37.0)$ & $0.008(0.17)$ \\
\hline & Yes & $243(68.8)$ & $169(74.4)$ & $57(57.6)$ & $17(63.0)$ & \\
\hline Frequency of healthcare use ${ }^{b}$ & & $1(2)$ & $1(2)$ & $1(1)$ & $1(1)$ & $0.69(0.05)$ \\
\hline \multirow[t]{2}{*}{ Nursing home admission } & No & $301(85.3)$ & 208 (91.6) & $75(75.8)$ & $18(66.7)$ & $<0.001(0.25)$ \\
\hline & Yes & $52(14.7)$ & $19(8.4)$ & $24(24.2)$ & $9(33.3)$ & \\
\hline
\end{tabular}

Statistical difference is reported in bold between categories of nutritional status $(p \leq 0.05)$

${ }^{\text {a }}$ mean (SD) is presented

${ }^{\mathrm{b}}$ median (IQR) is presented

MNA-SF mini nutritional assessment,-short form $Q O L$ quality of life, ED emergency department, HoLOS hospital length of stay 
categories. There was no difference in the number of participants in the age groups $(60-74,75-84$, and $85+$ years) between the MNA-SF categories. Results suggest that those who were screened as being malnourished had poorer QOL scores (EQ-5D 15 (6.0) vs 12 (7) and 11 (6.0), $p<0.001$; EQ-VAS 50 (20) vs 50 (30) and $65(30), \mathrm{p}<0.001)$, were more frail (Clinical Frailty Score $5.6(1.1)$ vs 4.5 (3.7) and $3.7(1.2), \mathrm{p}<$ 0.001 ), more at risk of adverse health outcomes (ISAR score 3.7 (1.2) vs 2.8 (1.3) and 2.3 (1.2), $p<0.001)$, had poorer functional status (Barthel score 13.0 (9.0) vs 17.0 (6.0) and $18.0(5.0), \mathrm{p}<0.001)$, and longer waiting times in the ED (PET 22.6 (11.4) vs 18.1 (17.2) and 17.2 (14.4) hours, $\mathrm{p}<0.001)$ compared to older adults who were at risk of malnutrition or had normal nutritional status, respectively. Those who had normal nutrition status were less likely to be discharged home from the ED (20.3\% $(n=46)$ vs $40.4 \%(n=40)$ and $33.3 \%(n=9), \mathrm{p}<0.001)$ compared to older adults who were screened at risk of malnutrition or had malnutrition, respectively.

Differences in follow-up outcomes between MNA-SF categories Table 4 presents the outcomes measured at 30-day follow-up since the index ED visit and differences between MNA-SF categories. In general, those who were malnourished were more likely to have reported a hospital admission $(29.6 \%(n=8)$ vs $12.1 \%(n=12)$ and $10.6 \%(n=24), p=0.02)$, a nursing home admission (33.3\% $(n=9)$ vs $24.4 \%(\mathrm{n}=24)$ and $8.4 \%(n=19), p<$ $0.001)$, a reduced quality of life $(40 \%(n=10)$ vs $15.1 \%$ $(n=13)$ and $13.3 \%(n=28), \mathrm{p}=0.02)$ and reduced functional status $(52 \%(\mathrm{n}=13)$ vs $36 \%(n=31)$ and $24.8 \%$ $(n=52), \mathrm{p}=0.02)$, compared to the older adults who were at risk of malnutrition or had normal nutritional status, respectively.

While similar patterns were observed at 6 months, with those categorised as being malnourished most at risk of functional decline, these differences between the MNA-SF and 6-month outcomes were not statistically significant (Appendix in Table 7).

\section{Malnutrition status as a predictor of reported decline in functional status and quality of life}

Hierarchical logistic regression models were used to analyse associations between MNA-SF categories of nutritional status and the reported decline in functional status and quality of life at 30-day follow up. Table 5 shows the models of declining functional status and MNA-SF categories controlling for sex, age, quality of life, risk of adverse health outcomes and frailty. The patients who were screened as malnourished in the ED were over three times more likely to have functional decline at follow-up, when compared to the patients who were identified as having a normal nutritional status in the ED (Model 1; unadjusted OR of 3.29 (95\% CI $=1.41$, 7.66), $p=0.008$ ). However, when controlling for sex, age, quality of life, risk of adverse health outcomes and frailty, malnutrition was no longer a significant predictor of functional decline (Model 3; unadjusted OR of 1.53 $(95 \% \mathrm{CI}=0.57,4.13) p=0.61$,$) .$

Table 5 Logistic regression model of decline in functional status (measured as Barthel Index) among older adults at 30-day follow up from index visit to the ED"

\begin{tabular}{|c|c|c|c|c|c|c|c|}
\hline & & \multicolumn{6}{|l|}{ 30-day follow up } \\
\hline & & \multicolumn{2}{|l|}{ Model 1} & \multicolumn{2}{|l|}{ Model 2} & \multicolumn{2}{|l|}{ Model 3} \\
\hline & & OR ( $95 \% \mathrm{Cl}$ OR) & p-value & OR (95\% Cl OR) & p-value & OR (95\% OR) & p-value \\
\hline \multirow[t]{3}{*}{ MNA categories } & Normal nutritional status & 1 & 0.008 & 1 & 0.02 & 1 & 0.61 \\
\hline & At risk of malnutrition & $1.71(1.00,2.94)$ & & $1.71(0.98,3.00)$ & & $1.27(0.68,2.36)$ & \\
\hline & Malnourished & $3.29(1.41,7.66)$ & & $3.08(1.28,7.39)$ & & $1.53(0.57,4.13)$ & \\
\hline \multirow[t]{2}{*}{ Sex } & Male & & & 1 & 0.12 & 1 & 0.07 \\
\hline & Female & & & $0.67(0.40,1.11)$ & & $0.61(0.36,1.01)$ & \\
\hline \multirow[t]{3}{*}{ Age } & $60-74$ & & & 1 & $<0.001$ & 1 & 0.002 \\
\hline & $75-84$ & & & $2.98(1.36,6.51)$ & & $3.50(1.53,8.01)$ & \\
\hline & $85+$ & & & $5.34(2.33,12.22)$ & & $5.20(2.11,12.78)$ & \\
\hline EQ-5D score & & & & & & $1.08(1.01,1.15)$ & 0.04 \\
\hline EQ VAS score & & & & & & $0.99(0.98,1.01)$ & 0.31 \\
\hline ISAR score & & & & & & $0.92(0.68,1.23)$ & 0.56 \\
\hline Clinical Frailty score & & & & & & $1.38(1.03,1.85)$ & 0.03 \\
\hline
\end{tabular}

Statistical significance if $\mathrm{p} \leq 0.05$

Model 2 controlling for sex and age

Model 3 controlling for sex, age, quality of life (EQ-5D and EQ-VAS), risk of adverse health (ISAR score) and frailty (CFI score)

$O R$ odds ratio, $C l$ confidence interval, MNA mini nutritional assessment, EQ-5D total quality of life score, EQ VAS visual analogue scale score, ISAR score identification of seniors at risk 
Table 6 shows the models of reported decline in quality of life at 30-days follow up and MNA-SF categories controlling for sex, age, functional ability, risk of adverse health outcomes and frailty. Patients who were identified as malnourished in the ED, were over four times more likely to report a decline in quality of life when compared to patients who were identified as having a normal nutritional status (Model 1; unadjusted OR of 4.33 (95\% $\mathrm{CI}=1.77,10.59), p=0.005)$. Furthermore, patients are more likely to report a significant decline in quality of life when confounding factors including sex, age, functional status and frailty are accounted for (Model 3; adjusted OR of $3.66(95 \% \mathrm{CI}=1.27,10.56), p=0.02)$.

\section{Discussion}

This is the first Irish study to screen for malnutrition in a cohort of older adults presenting to a large urban ED. We also provide observations of impact on patient outcomes between categories of nutrition status. Over one in three older adults defined as 'lower urgency' on admission were at risk of malnutrition or categorised as malnourished. These older adults were more likely to be frail and at risk of adverse health outcomes, to have experienced a fall in the previous three months, had hospital admissions in the previous six months and reported a poorer functional status and quality of life and spent more hours in the ED. Older adults screened as malnourished at the index ED visit were found to more frequently report decline in functional status and quality of life, and subsequent hospital and nursing home admissions at 30-day follow up compared to those categorised with a normal nutrition status. Furthermore, malnourished older adults were over three times more likely to report a significant decline in their quality of life at 30-days than those categorised with normal nutrition status independent of age, sex, risk of adverse health outcomes, frailty and functional status.

The number of older people $(n=27,7.6 \%)$ found to be malnourished in our study could be described as small. However, we also report a prevalence of risk of malnutrition among older adults $(n=99,28 \%)$ representing over a third of the admissions to the ED of lower urgency, medically stable, and cognitively intact older adults as nutritionally vulnerable. A decrease in food intake and weight loss among one in five participants was reported for the three months previous to admission in the ED (Table 2). A continuum of nutritional vulnerability among older adults has previously been described with subjects at risk considered likely to develop malnutrition in the near future $[11,21]$. Prevalence rates of malnutrition in ED settings in the USA and Australia have been reported as $12-16 \%[15,17,18,29]$. However, a point of difference between the current study and these other studies is that screening for malnutrition was conducted by research assistants or dietitians trained in nutrition screening and that may affect the accuracy in identifying patients with malnutrition risk [21, $28,30]$. Our study could be described as pragmatic in nature reflecting the realities in clinical practice that nutrition screening may be carried out by clinical staff who are not trained in nutritional assessment.

Screening for malnutrition is an important step in recognising and identifying risk of or diagnosis of malnourishment [8]. However, it is often not completed owing to

Table 6 Logistic regression model of decline in quality of life (EQ-5D) among older adults at 30-day follow up from index visit to the ED

\begin{tabular}{|c|c|c|c|c|c|c|c|}
\hline & & \multicolumn{6}{|l|}{ 30-day follow up } \\
\hline & & \multicolumn{2}{|l|}{ Model 1} & \multicolumn{2}{|l|}{ Model 2} & \multicolumn{2}{|l|}{ Model 3} \\
\hline & & OR (95\% Cl OR) & $\overline{p \text {-value }}$ & OR $(95 \% \mathrm{Cl}$ OR) & $p$-value & OR (95\% Cl OR) & $\overline{p \text {-value }}$ \\
\hline \multirow[t]{3}{*}{ MNA-SF categories } & Normal nutritional status & 1 & 0.005 & 1 & 0.008 & 1 & 0.02 \\
\hline & At risk of malnutrition & $1.16(0.57,2.36)$ & & $1.14(0.55,2.36)$ & & $1.00(0.46,2.15)$ & \\
\hline & Malnourished & $4.33(1.77,10.59)$ & & $4.32(1.70,10.95)$ & & $3.66(1.27,10.55)$ & \\
\hline \multirow[t]{2}{*}{ Sex } & Male & & & 1 & 0.08 & 1 & 0.07 \\
\hline & Female & & & $0.57(0.30,1.08)$ & & $0.55(0.29,1.05)$ & \\
\hline \multirow[t]{3}{*}{ Age } & $60-74$ & & & 1 & 0.03 & 1 & 0.05 \\
\hline & $75-84$ & & & $3.28(1.09,9.90)$ & & $3.11(1.02,9.47)$ & \\
\hline & $85+$ & & & $4.82(1.54,15.11)$ & & $4.42(1.37,14.24)$ & \\
\hline Barthel Index & & & & & & $1.10(0.71,1.45)$ & 0.12 \\
\hline ISAR score & & & & & & $1.01(0.71,1.45)$ & 0.94 \\
\hline Clinical Frailty score & & & & & & $1.33(0.91,1.95)$ & 0.14 \\
\hline
\end{tabular}

Statistical significance if $p \leq 0.05$

Model 2 controlling for sex and age

Model 3 controlling for sex, age, functional ability (Barthel Index), risk of adverse health (ISAR score) and frailty

$O R$ odds ratio, $C$ confidence interval, MNA-SF mini nutritional assessment-short form, ISAR score identification of seniors at risk 
perceived barriers of screening implementation in hospital settings including time, competence and resources [31, 32]. Most of the studies advocating for screening, do so at the ward level, thus potentially missing those who present via ED and are not admitted to the ward [15]. The estimated cost of care for patients with malnutrition in Ireland has been estimated at $€ 1.4$ billion, representing $10 \%$ of total healthcare costs with most of the cost (70\%) arising in the acute hospital or residential care settings [33]. A recent budget impact analysis has indicated that the implementation of hospital inpatient guidelines for nutrition screening and use of oral nutrition supplements could produce a net cost saving from reduced length of stay by an average of $13.9 \%$ in malnourished patients [34]. Malnutrition on admission develops in the community and is likely to be largely unaffected by the implementation of screening programmes in the acute sector [34]. Our study would indicate that the ED should be included in nutrition screening programmes as an earlier opportunity to identify and intervene given the reported increase in hospital and healthcare use and admission observed among older adults screened as malnourished.

A more recent and rapidly growing phenomenon is malnutrition concomitant with obesity in older adults [11]. Our study reflected the realities of clinical practice in the ED and body weight and height were measured when the equipment was available and it was feasible to remove the patient from the bed. Therefore, only forty-nine participants had measurements of weight and height taken to measure BMI despite the majority indicating an ability to get out of bed/chair. Nonetheless, $13 \%(n=4)$ of those who were classified as overweight/obese based on BMI were at risk of malnutrition. If BMI was relied upon as a sole indicator of nutrition, it would fail to identify nutritional issues in these individuals. This has also been reported in other studies highlighting that older people can be at nutritional risk although they may be overweight or obese $[8,35,36]$.

Any approach to managing nutritional risk needs to be multi-faceted and include the management of comorbidities, the provision of home and social supports to encourage and facilitate food intake and the implementation of dietary modifications to improve diet quality [35]. Intervention coordinated by an ED registered dietitian providing nutrition support to older adults identified at nutritional risk at presentation to a hospital setting may lead to improved patient outcomes [15]. Consistent with this, interventions designed to improve and sustain optimal nutritional status can also lead to significant improvements in quality of life, for both physical and mental aspects $[13,21]$.

\section{Limitations}

This study has several limitations. We did not perform a test of the inter-rater reliability of the administration of the MNA-SF, which has not been validated in the ED, although it has been validated in older adults across a variety of settings [20]. A finding from this study was the high proportion of older adults categorised as having a risk of malnutrition $(n=40,40.4 \%)$ or malnourished $(n=9,33.3 \%)$ that were discharged from the ED. As this study was observational and nutritional screening was conducted by staff who were not trained in diagnosing malnutrition we surmise that the need for further intervention was not recognised. It is previously reported that clinical staff can miss malnutrition in older adults due to a lack of routine nutritional screening in many hospitals $[17,21,37]$, and a belief by clinical staff that individual judgement of nutritional status is more superior to screening [38, 39].

Older adults who presented to the ED outside of core HSCP working hours ( 8 am to $5 \mathrm{pm}$, Monday to Friday) were not included in this study and therefore it is possible that eligible participants were missed. Also, older adults who were medically unstable or found to be moderately or severely cognitively impaired were excluded from the study. These groups represent a subgroup of older adults that are likely to be at a high risk of malnutrition as a consequence of reduced dietary intake in combination with the effects of catabolic disease $[8,12]$. The prevalence of malnutrition among older adults is known to increase with deteriorating functional and health status [21]. We do not know from this study if the observed prevalence of malnutrition was a cause or consequence of the reported decline in quality of life and adverse patient outcomes at follow-up. However, the increased association would indicate the need for further exploration as the assessment of quality of life is recognised as a clinically relevant outcome measure when evaluating intervention in patient populations, particularly older adults [13].

\section{Conclusions}

This study provides preliminary data that over one in three older adults presenting to an Irish emergency department were at risk of malnutrition or classed as malnourished and more likely to suffer adverse outcomes at follow up including declining health and an increased use of health care services. The findings add support to the prioritisation of nutritional screening in clinical practice and public health policy for older adults, particularly targeted towards high risk groups with frailty and multi-morbidity, and at increased risk of functional decline. Further research on a larger sample is recommended to confirm that findings from this study and future research to assess the feasibility and value of integrating ED-based dietetic intervention and impact on patient outcomes among this high risk group with malnutrition. 


\section{Appendix}

Table 7 Differences in reported patient outcomes across MNA-SF categories among 353 older adults at 6 month follow-up from index visit in an Irish ED. There were no differences between the MNA categories and the 6-month outcomes

\begin{tabular}{|c|c|c|c|c|c|c|}
\hline \multicolumn{7}{|c|}{ Differences in 6-month follow-up outcomes by MNA category } \\
\hline & & \multirow{2}{*}{$\begin{array}{l}\text { Full } \\
\text { Sample } \\
(n=353)\end{array}$} & \multirow[b]{2}{*}{$\begin{array}{l}\text { Normal nutrition } \\
(n=227)\end{array}$} & \multicolumn{2}{|l|}{ MNA categories } & \multirow[b]{2}{*}{$\begin{array}{l}\text { p-value } \\
\text { (Effect size) }\end{array}$} \\
\hline & & & & $\begin{array}{l}\text { At risk of malnutrition } \\
(n=99)\end{array}$ & $\begin{array}{l}\text { Malnourished } \\
(n=27)\end{array}$ & \\
\hline \multirow[t]{3}{*}{ Functional decline } & No change & $136(44.9)$ & $98(48.5)$ & $31(39.7)$ & $7(30.4)$ & $0.05(0.13)$ \\
\hline & Reduced function & $94(31.0)$ & $56(27.7)$ & $25(32.1)$ & $13(56.5)$ & \\
\hline & Improved function & $73(24.1)$ & $48(23.8)$ & $22(28.3)$ & $3(13.0)$ & \\
\hline \multirow[t]{3}{*}{ QOL decline } & No change & $76(25.2)$ & $57(28.2)$ & $17(22.1)$ & $2(8.7)$ & $0.07(0.12)$ \\
\hline & Reduced QOL & $85(28.1)$ & $57(28.2)$ & $24(31.2)$ & $4(17.4)$ & \\
\hline & Improved QOL & $141(46.7)$ & $88(43.6)$ & $36(46.8)$ & $17(73.9)$ & \\
\hline \multirow[t]{2}{*}{ ED revisit } & No & $221(63.3)$ & $150(66.7)$ & $53(54.6)$ & $18(66.7)$ & $0.11(0.11)$ \\
\hline & Yes & $128(36.7)$ & $75(33.3)$ & $44(45.4)$ & $9(33.3)$ & \\
\hline \multirow[t]{3}{*}{ Number of ED visits } & 0 & $221(63.3)$ & $151(67.1)$ & $52(53.6)$ & $18(66.7)$ & $0.16(0.10)$ \\
\hline & 1 & $90(25.5))$ & $54(24.0)$ & $31(32.0)$ & $5(18.5)$ & \\
\hline & $2+$ & $38(10.9)$ & $20(8.9)$ & $14(14.4)$ & $4(14.8)$ & \\
\hline \multirow[t]{2}{*}{ Hospital admissions } & No & $258(73.9)$ & $173(76.9)$ & $66(68.0)$ & $19(70.4)$ & $0.23(0.09)$ \\
\hline & Yes & $91(26.1)$ & $52(23.1)$ & $31(32.0)$ & $8(29.6)$ & \\
\hline HoLOS at revisit ${ }^{a}$ & & $12(19)$ & $9(20.0)$ & $13(17.5)$ & $8.5(64.25)$ & $0.51(0.15)$ \\
\hline \multirow[t]{2}{*}{ Healthcare use } & No & $78(22.3)$ & $40(17.8)$ & $25(25.8)$ & $13(48.1)$ & $0.001(0.20)$ \\
\hline & Yes & $271(77.7)$ & $185(82.2)$ & $72(74.2)$ & $14(51.9)$ & \\
\hline Frequency of healthcare use $\mathrm{e}^{\mathrm{a}}$ & & $5(8)$ & $7(9.0)$ & $3.5(4.0)$ & $3(9.5)$ & $0.72(0.05)$ \\
\hline \multirow[t]{2}{*}{ Nursing home admission } & No & 335 (96.0) & $216(96.0)$ & $93(95.9)$ & $26(96.3)$ & $0.99(0.01)$ \\
\hline & Yes & $14(4.0)$ & $9(4.0)$ & $4(4.1)$ & $1(3.7)$ & \\
\hline
\end{tabular}

amedian (IQR) is presented

MNA mini nutritional assessment, $Q O L$ quality of life, $E D$ emergency department, HoLOS hospital length of stay

\section{Abbreviations}

BMI: Body Mass Index; CC: Calf Circumference; CFS: Clinical Frailty Score; ED: Emergency Department; EQ-5D-5L: EuroQoL Health Related Quality of Life instrument; EQ-Vas: EuroQoL Visual Analogue Scale; ESPEN: European Society for Parenteral and Enteral Nutrition; HSE: Health Service Executive; HoLOS: Hospital Length of Stay; HSCP: Health and Social Care Professional; ISAR: Identification of Seniors At Risk; MNA: Mini Nutritional Assessment; PET: Patient length of stay in the emergency department; QOL: Quality of Life

\section{Acknowledgments}

This analysis was conducted using data from The OPTI-MEND study. We would like to acknowledge the OPTI-MEND investigators for co-ordinating the original investigation, data collectors, staff and patients at the Emergency Department, University Hospital Limerick.

\section{Authors' contributions}

$R G, M O ' C$ \& DR designed the original study. RG, AG \& AT conceived the idea for this secondary analysis. AG wrote the manuscript. AON performed the data analysis. RG, AT \& MO'C contributed to the critical appraisal of the final manuscript. All authors read and approved the final manuscript.

\section{Funding}

The OPTI-MEND study is supported by the Health Research Board of Ireland through the Research Collaborative for Quality and Patient Safety (RCQPS) 2017. The sponsor is not involved in the design of the study and collection, analysis, interpretation of data, or in writing the manuscript.
Availability of data and materials

The OPTIMEND dataset is currently not publicly availably but any queries can be directed to the senior author and guarantor of the manuscript.

\section{Ethics approval and consent to participate}

The OPTI-MEND study received ethical approval from the Health Service Executive (HSE) Mid-Western Regional Hospital Research Ethics Committee (ref. 103/18). Written informed consent has been obtained from all study participants.

\section{Consent for publication}

Not applicable.

\section{Competing interests}

The authors declare that they have no competing interests.

\section{Author details}

${ }^{1}$ School of Allied Health, Faculty of Education and Health Sciences, Health Implementation Science and Technology, Health Research Institute,

University of Limerick, Limerick V94 T9PX, Ireland. ${ }^{2}$ School of Allied Health, Faculty of Education and Health Sciences, Ageing Research Centre, Health Research Institute, University of Limerick, Limerick, Ireland. ${ }^{3}$ Department of Ageing and Therapeutics, University Hospital Limerick, Dooradoyle, Limerick, Ireland. ${ }^{4}$ Graduate Entry Medical School, Faculty of Education and Health Sciences, University of Limerick, Limerick, Ireland. ${ }^{5}$ Retrieval, Emergency and Disaster Medicine Research and Development Unit (REDSPOT), Emergency Department, University Hospital Limerick, Dooradoyle, Limerick, Ireland. 
Received: 16 June 2020 Accepted: 26 October 2020

Published online: 07 November 2020

\section{References}

1. United Nations, Department of Economic and Social Affairs, Population Division (2019). World Population Prospects 2019: Highlights. ST/ESA/SER.A 423. Available from:http://www.population.un.org/wpp/Publications/Files/ WPP2019_Highlights.pdf. Accessed 7 April 2020.

2. Central Statistics Office. Central Statistics Office. Census 2016 Profile 3-An Age Profile of Ireland. Cork.: Central Statistics Office.; 2017. Available from: http://www.population.un.org/wpp/Publications/Files/WPP2019_Highlights. pdf. Accessed 13 Feb 2020

3. Central Statistics Office. Population and Labour Force Projections 2017-2051 Dublin: Central Statistics Office; 2017 Available from: https://www.cso.ie/en/ releasesandpublications/ep/p-plfp/populationandlabourforceprojections201 7-2051/populationprojectionsresults/. Accessed 16 Sept 2020.

4. van Tiel S, Rood PP, Bertoli-Avella AM, Erasmus V, Haagsma J, van Beeck E, et al. Systematic review of frequent users of emergency departments in non-US hospitals: state of the art. Eur J Emerg Med. 2015;22(5):306-15.

5. Morley C, Unwin M, Peterson GM, Stankovich J, Kinsman L. Emergency department crowding: a systematic review of causes, consequences and solutions. PLoS One. 2018:13(8):e0203316.

6. Roe L, Thomas S, Trépel D, Normand C. Trends in healthcare cover and healthcare use for older adults in Ireland during the austerity years of 20092016. Dublin: The Irish Longidudinal Study on Ageing; 2018.

7. Corish CA, Bardon LA. Malnutrition in older adults: screening and determinants. Proc Nutr Soc. 2019;78(3):372-9.

8. Volkert D, Beck AM, Cederholm T, Cruz-Jentoft A, Goisser S, Hooper L, et al. ESPEN guideline on clinical nutrition and hydration in geriatrics. Clin Nutr. 2019;38(1):10-47.

9. Söderström L, Rosenblad A, Adolfsson ET, Bergkvist L. Malnutrition is associated with increased mortality in older adults regardless of the cause of death. Br J Nutr. 2017;117(4):532-40.

10. Dent E, Visvanathan R, Piantadosi C, Chapman I. Nutritional screening tools as predictors of mortality, functional decline, and move to higher level care in older people: a systematic review. J Nutr Gerontol Geriatrics. 2012;31(2): 97-145.

11. Starr KNP, McDonald SR, Bales CW. Nutritional vulnerability in older adults: a continuum of concerns. Curr Nutr Rep. 2015;4(2):176-84.

12. Agarwal E, Miller M, Yaxley A, Isenring E. Malnutrition in the elderly: a narrative review. Maturitas. 2013;76(4):296-302

13. Rasheed S, Woods RT. Malnutrition and quality of life in older people: a systematic review and meta-analysis. Ageing Res Rev. 2013;12(2):561-6.

14. Abizanda P, Sinclair A, Barcons N, Lizán L, Rodríguez-Mañas L. Costs of malnutrition in institutionalized and community-dwelling older adults: a systematic review. J Am Med Dir Assoc. 2016;17(1):17-23.

15. Vivanti A, Isenring E, Baumann S, Powrie D, Neill M, Clark D, et al. Emergency department malnutrition screening and support model improves outcomes in a pilot randomised controlled trial. Emerg Med J. 2015:32(3):180

16. Gentile S, Lacroix O, Durand AC, Cretel E, Alazia M, Sambuc R, et al. Malnutrition: a highly predictive risk factor of short-term mortality in elderly presenting to the emergency department. J Nutr Health Aging. 2013;17(4): 290-4.

17. Pereira GF, Bulik CM, Weaver MA, Holland WC, Platts-Mills TF. Malnutrition among cognitively intact, noncritically ill older adults in the emergency department. Ann Emerg Med. 2015;65(1):85-91.

18. Burks CE, Jones CW, Braz VA, Swor RA, Richmond NL, Hwang KS, et al. Risk factors for malnutrition among older adults in the emergency department: a multicenter study. J Am Geriatr Soc. 2017;65(8):1741-7.

19. Drame M, Jovenin N, Novella JL, Lang PO, Somme D, Laniece I, et al. Predicting early mortality among elderly patients hospitalised in medical wards via emergency department: the SAFES cohort study. J Nutr Health Aging. 2008;12(8):599-604.

20. Kaiser MJ, Bauer JM, Ramsch C, Uter W, Guigoz Y, Cederholm T, et al. Validation of the mini nutritional assessment short-form (MNA-SF): a practical tool for identification of nutritional status. J Nutr Health Aging. 2009;13(9):782-8.

21. Volkert D. Malnutrition in older adults-urgent need for action: a plea for improving the nutritional situation of older adults. Gerontology. 2013;59(4): 328-33.
22. Cassarino RK, O'Shaughnessy I, Smalle E, White S, Devlin C, et al. A randomised controlled trial exploring the impact of a dedicated health and social care professionals team in the emergency department on the quality, safety, clinical and cost-effectiveness of care for older adults: a study protocol. Trials. 2019;20(1):591.

23. Parenti N, Reggiani MLB, lannone P, Percudani D, Dowding D. A systematic review on the validity and reliability of an emergency department triage scale, the Manchester triage system. Int J Nurs Stud. 2014;51(7):1062-9.

24. Rockwood K, Song X, MacKnight C, Bergman H, Hogan DB, McDowell I, et al. A global clinical measure of fitness and frailty in elderly people. Cmaj. 2005;173(5):489-95.

25. McCusker J, Bellavance F, Cardin S, Trepanier S, Verdon J, Ardman O. Detection of older people at increased risk of adverse health outcomes after an emergency visit: the ISAR screening tool. J Am Geriatr Soc. 1999; 47(10):1229-37.

26. Mahoney FI, Barthel DW. Functional evaluation: the barthel index. Maryland State Med J. 1965;14:61-5.

27. Rabin R, de Charro F. EQ-5D: a measure of health status from the EuroQol group. Ann Med. 2001;33(5):337-43.

28. Marshall S, Young A, Isenring E. The malnutrition screening tool in geriatric rehabilitation: a comparison of validity when completed by health professionals with and without malnutrition screening training has implications for practice. J Acad Nutr Diet. 2018;118(1):118-24.

29. Vivanti AP, McDonald CK, Palmer MA, Sinnott M. Malnutrition associated with increased risk of frail mechanical falls among older people presenting to an emergency department. Emerg Med Australasia. 2009;21(5):386-94.

30. Silver HJ, Pratt KJ, Bruno M, Lynch J, Mitchell K, McCauley SM. Effectiveness of the malnutrition quality improvement initiative on practitioner malnutrition knowledge and screening, diagnosis, and timeliness of malnutrition-related care provided to older adults admitted to a tertiary care facility: a pilot study. J Acad Nutr Diet. 2018;118(1):101-9.

31. Dent E, Wright $\mathrm{O}$, Hoogendijk EO, Hubbard RE. Nutritional screening and dietitian consultation rates in a geriatric evaluation and management unit. Nutr Dietetics. 2018;75(1):11-6.

32. Eide HD, Halvorsen K, Almendingen K. Barriers to nutritional care for the undernourished hospitalised elderly: perspectives of nurses. J Clin Nurs. 2015;24(5-6):696-706.

33. Rice $\mathrm{N}$, Normand $\mathrm{C}$. The cost associated with disease-related malnutrition in Ireland. Public Health Nutr. 2012;15(10):1966-72.

34. Rice N. National Clinical Guideline no. 22. Nutrition screeening and use of oral nutrition support for adults in the acute care setting. Annex 3: Budget Impact Analysis. Dublin: Department of Health; 2019.

35. Winter J, Flanagan D, McNaughton SA, Nowson C. Nutrition screening of older people in a community general practice, using the MNA-SF. J Nutr Health Aging. 2013;17(4):322-5.

36. Dent $\mathrm{E}$, Hoogendijk E, Visvanathan R, Wright O. Malnutrition screening and assessment in hospitalised older people: a review. J Nutr Health Aging. 2019;23(5):431-41.

37. Lindorff-Larsen K, Rasmussen HH, Kondrup J, Staun M, Ladefoged K, Group TSN. Management and perception of hospital undernutrition-a positive change among Danish doctors and nurses. Clin Nutr. 2007;26(3):371-8.

38. Porter J, Raja R, Cant R, Aroni R. Exploring issues influencing the use of the malnutrition universal screening tool by nurses in two Australian hospitals. J Hum Nutr Diet. 2009;22(3):203-9.

39. Green $\mathrm{S}$, James E. Barriers and facilitators to undertaking nutritional screening of patients: a systematic review. J Hum Nutr Diet. 2013;26(3):211-21.

\section{Publisher's Note}

Springer Nature remains neutral with regard to jurisdictional claims in published maps and institutional affiliations. 